\title{
Neurobiología de la adicción a psicoestimulantes
}

\author{
E. Fernández-Espejo
}

\section{THE NEUROBIOLOGY OF PSYCHOSTIMULANT ADDICTION}

\begin{abstract}
Summary. Introduction and development. Psychostimulant drugs encompass amphetamines, natural alkaloids like cocaine, and methyl-xanthynes. These drugs induce a strong dependence, manifested as sensitization and tolerance at a neurobiological level. Sensitization is currently being studied experimentally, and it is made up of two stages: initial induction and consolidated expression. During induction, the mesocorticolimbic circuit along with dopamine and glutamate changes in the ventral tegmentum play a critical role. During expression, addictive habits are consolidated through changes in the corticostriato-amygdaloid loop. Conclusion. All together leads to a consolidated addiction, considered as an anomalous learning process, along with a loss of control over drug taking. [REV NEUROL 2006; 43: 147-54]
\end{abstract}

Key words. Addiction. Dopamine. Drug. Glutamate. Habit. Psychostimulant. Sensitization.

\section{INTRODUCCIÓN}

Los psicoestimulantes son sustancias capaces de reducir los umbrales de alerta o de vigilia, de modo que el individuo responde con más facilidad o prontitud a los estímulos exógenos o endógenos. Los antidepresivos también elevan la capacidad de respuesta de la persona, aunque lo hacen sólo en aquellas cuyo humor y vitalidad se encuentran previa y patológicamente deprimidos. Los efectos subjetivos de todos los psicoestimulantes dependen de la personalidad del individuo, el medio en el cual se administran, la dosis y la vía de administración. Por ejemplo, en una persona normal, dosis moderadas de anfetamina (10$20 \mathrm{mg}$ ) producen euforia, una sensación de energía y alerta aumentada, anorexia, insomnio y una mejoría en la conducta de tareas repetitivas. Si la dosis aumenta, estos síntomas se hacen más marcados y la influencia del medio ambiente es menos pronunciada. La importancia de la drogadicción a psicoestimulantes en el mundo lo pone de manifiesto el informe de la Organización de las Naciones Unidas de 2005 sobre consumo de drogas, que estima unos 200 millones de adictos en el mundo, de los cuales 52 millones son adictos a los psicoestimulantes. Éstos producen una fuerte dependencia, en el grado 3 de la clasificación de la Organización Mundial de la Salud.

Hay diversos tipos de psicoestimulantes, que se clasifican en tres grandes familias: anfetamínicos, alcaloides naturales y metilxantinas (Tabla). Tanto la anfetamina como la cocaína producen efectos similares sobre el estado de ánimo, provocan toxicidad crónica y poseen un alto potencial de abuso y dependencia. Las metilxantinas son sustancias energizantes con menor riesgo y potencial de abuso.

\section{Anfetaminas}

La anfetamina es una fenilisopropilamina -cuyo isómero más potente a nivel central es el dextro-, sintetizada a finales de 1920 e introducida en clínica en 1930 . Se absorbe muy bien en el tracto gastrointestinal y por vía oral sus efectos euforizantes

\footnotetext{
Aceptado tras revisión externa: 22.05.06.

Departamento de Fisiología Médica. Facultad de Medicina. Universidad de Sevilla. Sevilla, España.

Correspondencia: Dr. Emilio Fernández Espejo. Departamento de Fisiología Médica. Facultad de Medicina. Universidad de Sevilla. Avda. Sánchez Pizjuán, 4. E-41009 Sevilla. Fax: +34954 551 769. E-mail: efespejo@us.es (C) 2006, REVISTA DE NEUROLOGÍA
}

aparecen a los 30-60 min y duran de 8 a $24 \mathrm{~h}$. Se hidroliza y desmetila en el hígado, y se elimina por la orina como p-hidroxiefedrina y norefedrina, y en parte sin metabolizar. La excreción aumenta notablemente al acidificar la orina. Su vida media es de unas $10 \mathrm{~h}$. Se administra también por vía intravenosa, por inhalación o fumada.

Los efectos estimulantes se deben a la estimulación de la liberación de dopamina, noradrenalina y serotonina desde la mayoría de las regiones cerebrales, influyendo también el hecho de que el transportador de aminas actúe de modo inverso, como se esquematiza en la figura 1 [1]. Además, posee débiles efectos inhibidores de la monoaminooxidasa y acciones directas en receptores dopaminérgicos. La fenfluramina es una anfetamina que estimula selectivamente la liberación de 5-HT, carece de propiedades estimulantes y dependencia, y se usa como anorexígeno.

Pueden emplearse terapéuticamente, aunque la anfetamina y sus análogos presentan escasas indicaciones terapéuticas: narcolepsia (anfetamina) y en los síndromes de déficit atencionales en la infancia (metilfenidato y pemolina). Las propiedades inhibidoras del centro del apetito han llevado al desarrollo de análogos para el tratamiento de la obesidad, muchos de los cuales se han descartado por sus efectos euforizantes y su riesgo de abuso.

\section{Cocaína}

La cocaína, metiléster de benzoilecgonina, es un alcaloide que se extrae de las hojas de dos arbustos de coca (Erythroxylum coca lam y Erythroxylum novogranatense), cultivados en las regiones tropicales de los Andes y consumidos ya por las civilizaciones preincaicas. Se importó a Europa en 1580 y su principio activo fue aislado en 1860 por Wöhler. Sus propiedades anestésicas locales se descubrieron en 1870. Los indios andinos mastican las hojas de coca con el fin de disminuir las sensaciones de hambre y de fatiga, mezclándolas con ceniza que, al ser alcalina, libera la base cocaína, que atraviesa fácilmente la mucosa de la boca. La cocaína suele consumirse en forma de clorhidrato, inhalada por vía intranasal o inyectada por vía intravenosa. Otra forma de consumo consiste en fumar la cocaína base. Los efectos de la cocaína intranasal se empiezan a percibir al cabo de 3-5 min y alcanzan su máximo a los 10-20 min. Fumada o por vía intravenosa se producen a los 8-10 s y desaparecen en pocos minutos. La rapidez de inicio y término otorga una gran capacidad reforzadora a estas vías. La cocaína se hidroliza en el plasma y también se metaboliza en el hígado. Su vida me- 
dia de eliminación es alrededor de $1 \mathrm{~h}$, aunque la duración de sus efectos se relaciona con su vida media de distribución, que es mucho más corta.

Se cree que los efectos reforzadores de la cocaína se deben a su capacidad de inhibir la recaptación de dopamina, noradrenalina y serotonina, por unirse al transportador de recaptación de aminas, como se esquematiza en la figura 1 [2]. Aumenta la actividad dopaminérgica, particularmente en el área tegmental ventral (ATV) y en el núcleo accumbens, o sea, en las principales áreas del sistema dopaminérgico mesocorticolímbico. También incrementa la actividad glutamatérgica en el núcleo accumbens, el ATV, el estriado y la corteza prefrontal [3].

\section{Cafeína y metilxantinas}

Los alcaloides metilxantínicos se encuentran en diversas plantas conocidas desde la antigüedad por su efecto de mejorar el ánimo y quitar el sueño y la fatiga, como el café, el guaraná, el cacao, la cola y el mate. Entre estos alcaloides destacan la teobromina, la teofilina, la cafeína y la teína. Las dos primeras son metilxantinas, y las dos últimas, derivados trimetílicos. Las metilxantinas son antagonistas de las acciones sedantes de la adenosina. Se piensa que el mecanismo de la excitación del sistema nervioso central producido por estos fármacos es consecuencia del bloqueo de receptores de adenosina. Son antihipnóticos, analépticos, vasodilatadores y estimuladores cardíacos. También son broncodilatadores y diuréticos, de acciones moderadas y poco riesgo.

La cafeína es la principal metilxantina y el ingrediente psicoactivo del café, el chocolate y las bebidas de cola. Se absorbe bien por vía oral. La concentración máxima se alcanza a los 30-45 min de la ingestión. Su vida media es de una $3 \mathrm{~h}$ y se metaboliza en un $90 \%$. La cafeína produce alerta aumentada, disminución del sueño, el cansancio y la fatiga, pudiendo aumentar la capacidad de realización de determinadas tareas. En dosis mayores produce excitación, ansiedad e insomnio. Al igual que otras xantinas, presenta acción diurética, inotrópica positiva, cronotrópica positiva y broncodilatadora. En dosis bajas produce una sensación aumentada de bienestar y capacidad mental. Con dosis mayores puede desarrollarse irritabilidad, temblor fisiológico e hiperactividad refleja. Los efectos dependen de la sensibilidad del individuo y la velocidad de metabolización.

El consumo crónico provoca tolerancia y dependencia física. La suspensión de 1-4 tazas de café en la mañana, en un usuario regular, origina pereza mental, sentimientos de depresión e incapacidad para pensar, escribir o desarrollar procedimientos cognitivos de una forma coherente. En los grandes consumidores de café se ha descrito la aparición de un síndrome de abstinencia, que se caracteriza por cefaleas, ansiedad, irritabilidad y letargia. Estos síntomas se alivian rápidamente ingiriendo cafeína, lo que demuestra que se trata de un síndrome de abstinencia.

\section{Efectos farmacológicos y dependencia de anfetamina y cocaína}

Cuando se fuman o se inyectan por vía intravenosa, la metanfetamina y la cocaína producen casi inmediatamente una intensa sensación de placer, conocida como rush ('subidón'), comparable al orgasmo. Se sigue de una sensación de aumento de la energía y del estado de alerta, que se acompaña de disminución del apetito y de la sensación subjetiva de cansancio. También disminuye el tiempo de sueño, sobre todo la fase REM. Se experimenta un aumento subjetivo de las capacidades y habilidades. A medida que la reacción eufórica desaparece, se experimenta una sensación de disforia y decaimiento, más pronunciada cuanto más rápidos o intensos han sido los efectos. Este cuadro se acompaña del deseo intenso de volver a experimentar los efectos. Cuando estas drogas se aspiran no hay rush y la euforia tarda más en aparecer. La metanfetamina origina estos mismos efectos por vía oral. Pueden producir nerviosismo, agitación, temblor, fiebre, insomnio, confusión y, en algunos casos, estados de delirio y de pánico, e incluso ideación paranoide. La metanfetamina (MDA) y la metilenedioximetanfetamina (MDMA) 
son neurotóxicas en animales, dañando las neuronas dopaminérgicas y serotoninérgicas, pero la cocaína parece no tener efectos neurotóxicos (excepto en altas dosis). La anfetamina estimula el generador respiratorio y tiene acción anticinetósica. La cocaína prolonga la euforia del alcohol y mejora algunos de sus efectos depresores, además de poseer propiedades anestésicas locales. Periféricamente ejercen efectos $\alpha$ y $\beta$-adrenérgicos: taquicardia, hipertensión asistólica y diastólica, vasoconstricción, midriasis, aumento de la glicemia y de la temperatura, contracción de esfínteres y retraso digestivo.

Respecto a la dependencia, el abuso de anfetaminas comenzó en los años cuarenta con el uso de inhaladores descongestionantes nasales. En la Segunda Guerra Mundial se empleó para disminuir la fatiga y aumentar el rendimiento de los soldados. Al terminar la guerra quedó un gran stock a disposición de la población civil. El consumo de anfetaminas por vía oral se ha dado típicamente en estudiantes, conductores de camiones y deportistas. Los grandes consumidores de anfetamina y cocaína tienden a presentar ciclos en que se alternan períodos de gran consumo, en que apenas comen o duermen, con otros libres de consumo. También se presentan patrones de uso circunstancial que pueden producir dependencia, con graves alteraciones médicas y psiquiátricas. La anfetamina puede administrarse por vía intravenosa, fumarse como cristales (ice) o inhalarse. Existen dos formas de administración de cocaína: aspirar una línea de clorhidrato o fumar la pasta base, la cual se obtiene alcalinizando la sal y extrayendo la base con solventes orgánicos. La vía intravenosa se usa raramente por el peligro de sobredosis.

Las sobredosis de anfetamina rara vez son letales y pueden controlarse con antipsicóticos como el haloperidol; el peligro lo constituyen la hemorragia cerebral y el daño renal. Los poderosos efectos vasoconstrictores de la cocaína pueden ocasionar hipertensión aguda grave, infarto de miocardio y apoplejía. La acción anestésica local contribuye a las convulsiones. Las víctimas fallecen en minutos por arritmias, depresión respiratoria o convulsiones. El tratamiento es con diacepam, propranolol o bloqueadores de canales de calcio.

\section{Sensibilización y tolerancia}

La sensibilización ocurre con todos los psicoestimulantes, en gran parte debida a hiperfunción dopaminérgica corticolímbica, por ejemplo, el incremento de la conducta motora estereotipada que se observa en abusadores de anfetaminas, así como la progresiva aparición de alteraciones de la personalidad y síntomas psicóticos tras el consumo crónico de cocaína o anfetamina. Los primeros cambios que aparecen son de tipo ansioso y/o depresivo, con confusión, agresividad y pérdida de interés por la mayoría de las actividades. Se pueden producir psicosis tóxicas, con alucinaciones visuales y táctiles e ilusiones paranoides. Para el tratamiento puede recurrirse a fármacos antipsicóticos. El proceso de sensibilización se está estudiando experimentalmente de modo intensivo en el ámbito bioquímico y conductual, pues se considera en la actualidad que representa la expresión de cambios plásticos cerebrales debidos al consumo crónico de droga y subyace al incremento del valor motivacional de la droga (efecto incentivo), así como a los fenómenos de abstinencia y recaída una vez que se abandona la droga [4-7]. La neurobiología de la sensibilización se trata más profundamente con posterioridad.

La tolerancia es la disminución progresiva de efectos de la droga. La mayoría de los usuarios requieren dosis crecientes para producir los mismos efectos subjetivos experimentados al iniciar la ingesta, pues se desarrolla tolerancia a algunos de los efectos centrales, como euforia y anorexia. La tolerancia se debe probablemente a una excreción aumentada de la droga, aunque han de intervenir fenómenos neuroquímicos adaptativos en el sistema nervioso. Existe tolerancia cruzada entre psicoestimulantes.

\section{BASES NEUROBIOLÓGICAS DE LA ADICCIÓN A PSICOESTIMULANTES}

Se tratan las bases neurobiológicas de la sensibilización a psicoestimulantes, un fenómeno muy estudiado y que está revelando claves importantes sobre los cambios neuronales y bioquímicos cerebrales que subyacen al desarrollo del proceso adictivo.

\section{La adicción a psicoestimulantes se fundamenta en un fenómeno de sensibilización con dos fases: inducción y expresión}

La exposición repetida a psicoestimulantes induce un aumento progresivo de la actividad motora en numerosas especies, incluido el ser humano. Este fenómeno se denomina 'sensibilización conductual', y se asocia a cambios plásticos en circuitos nerviosos que, por otra parte, incrementan el valor motivacional de las drogas y además subyacen al fenómeno de ansia de droga (craving) una vez que se abandona el consumo, como ya se ha comentado [4-7]. Estos cambios plásticos neuronales son motivo de intenso estudio. El proceso adictivo consta de una fase de inducción, durante el consumo inicial de la droga, y otra de expresión, durante la consolidación de la adicción. Ambos fenómenos constan de mecanismos neuroquímicos y moleculares diferentes. En la inducción participa de modo crítico el circuito mesocorticolímbico, y en ella se establecen cambios bioquímicos que fundamentan la sensibilización y facilitan el aprendizaje adictivo. En la expresión, destaca el bucle corticoestriatoamigdalino, y en esta fase se desarrollan los cambios bioquímicos que generan el hábito adictivo, como conducta patológica consolidada. Además, se consolida la sensibilización y también aparecen fenómenos de tolerancia.

Uno de los efectos directos de los psicoestimulantes es el incremento de la transmisión dopaminérgica en el circuito mesocorticolímbico, que nace en el ATV y se dirige a áreas limbicomotoras (Fig. 2). Este efecto está mediado por la inhibición de la recaptación de dopamina con aumento de su disponibilidad en la biofase neuronal, y este fenómeno se asocia claramente a la sensibilización a psicoestimulantes, tanto durante la fase de inducción como la de expresión [8]. Sin embargo, el proceso sensibilizador es más complejo que el simple cambio en una vía de neurotransmisión, y los resultados de cientos de experimentos indican que la sensibilización se debe a la interacción de diversos neurotransmisores, neuropéptidos, factores neurotróficos, sus receptores y sus vías de señalización intracelular. Hasta la fecha, la interacción entre dopamina y glutamato en el ATV durante la fase de inducción a la sensibilización ha sido la más estudiada.

\section{La fase de inducción de la sensibilización está mediada por cambios en la transmisión de dopamina y glutamato en el tegmento ventral}

La administración de cocaína y anfetamina induce un incremento de los niveles de dopamina en el ATV, y la administración repetida incrementa aún más la actividad dopaminérgica en esta 
región. Este efecto es transitorio, pues dura 4-6 días de administración diaria, y no se observa al 14. ${ }^{\circ}$ día [9]. El incremento inicial transitorio en la liberación de dopamina puede deberse a una desensibilización de los autorreceptores $\mathrm{D}_{2}$ de las neuronas de dopamina, que induce despolarización y excitación celular por cierre de canales de potasio [10]. De hecho, la administración del agonista $D_{2}$ quimpirol incrementa el efecto de la cocaína, pues facilita la desensibilización de estos receptores [11], y si se bloquea la despolarización mediante baclofeno (agonista GABA), se anula la sensibilización [8]. Los receptores $\mathrm{D}_{1}$ también están involucrados, puesto que los antagonistas o agonistas $\mathrm{D}_{1}$ anulan o incrementan la sensibilización a cocaína, respectivamente [12-14]. Los receptores $\mathrm{D}_{1}$ modulan la liberación de glutamato y destaca el hecho de que no hay receptores

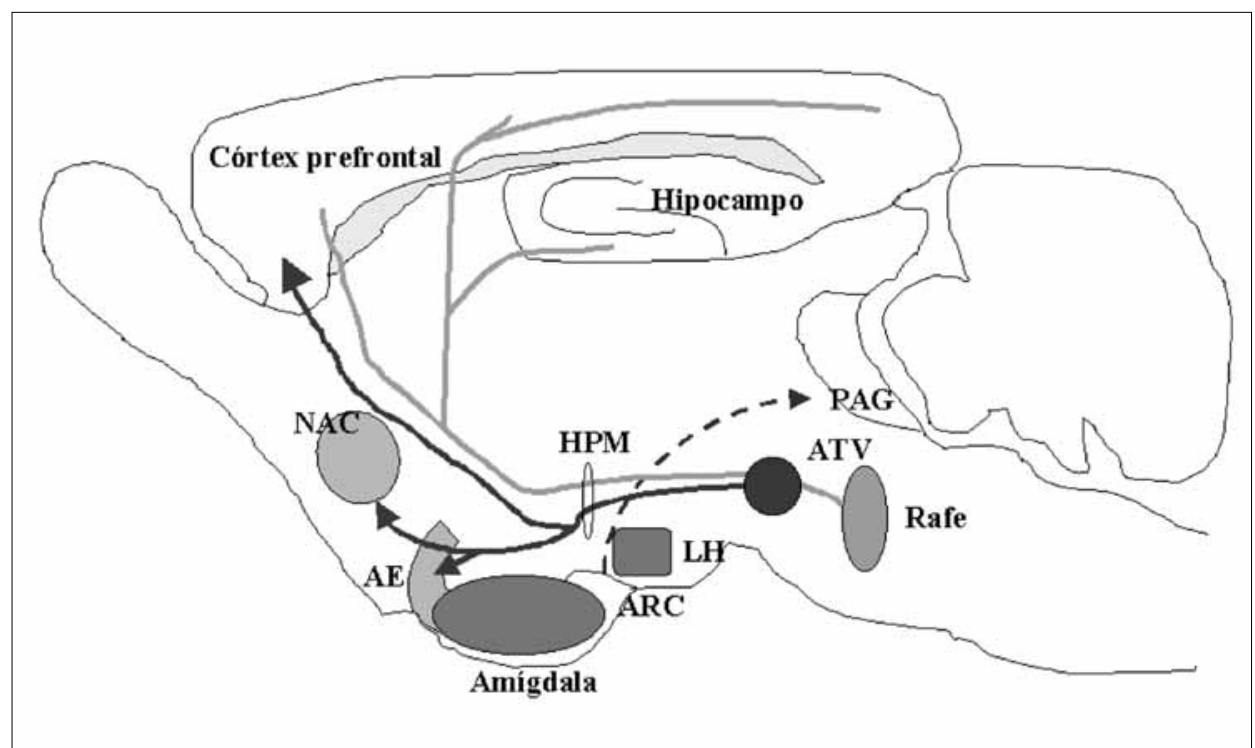

Figura 2. Centros y circuitos nerviosos que participan en la adicción a psicoestimulantes, en el cerebro de rata. La vía mesocorticolímbica dopaminérgica (línea negra gruesa) nace en el área tegmental ventral (ATV) y se dirige al núcleo accumbens (NAC), la amígdala extendida (AE) y el córtex prefrontal, siendo crítica en el proceso adictivo a las drogas. Las vías serotoninérgicas cerebrales parten de los núcleos del rafe (línea gris gruesa) y se extienden por casi todo el córtex cerebral. Las fibras dopaminérgicas mesocorticolímbicas y las serotoninérgicas discurren por el haz prosencefálico medial (HPM). El hipotálamo y el área periacueductal (PAG) son otros centros implicados en el proceso adictivo. El hipotálamo lateral (LH) y el núcleo arcuato (ARC), así como la vía $\beta$-endorfínica que nace en dicho núcleo (línea discontinua) y que se dirige a la PAG, se cree que están involucrados también en el proceso adictivo (modificado de [29]).

$\mathrm{D}_{1}$ en las neuronas de dopamina

del ATV, sino que se sitúan en las terminales de glutamato procedentes de la corteza prefrontal y del tegmento laterodorsal. Esto permite creer que la acción de la dopamina sobre receptores $\mathrm{D}_{1}$ presinápticos incrementa la liberación de glutamato en el ATV, hecho que es apoyado por la evidencia experimental que la acción sensibilizadora del glutamato en el ATV tras cocaína y anfetamina se bloquea con antagonistas $D_{1}$. Se sabe que existe un efecto transitorio con aumento de la actividad de glutamato en el ATV, con aumento de las corrientes a través de receptores AMPA de glutamato en las neuronas de dopamina (esto, a su vez, despolariza las células y mantiene la excitación neuronal). Inicialmente se pensó que la actividad glutamatérgica aumentada procedía de las terminales de la corteza prefrontal, pues la lesión de ésta anula la inducción de la sensibilización. Actualmente se sabe que la corteza prefrontal no proyecta directamente a las neuronas dopaminérgicas del ATV. El efecto podría ser indirecto, de modo que se incrementa la actividad de glutamato de fibras procedentes del tegmento laterodorsal, que a su vez son excitadas por fibras glutamatérgicas de la corteza prefrontal [15].

En definitiva, el incremento en la actividad de dopamina en el ATV tras psicoestimulantes, facilitada por despolarización neuronal, estimula receptores $\mathrm{D}_{1}$ presinápticos que ocasionan una mayor liberación local de glutamato, lo que a su vez estimula aún más las neuronas de dopamina del ATV, constituyendo estos hechos un ciclo fundamental en la inducción de la sensibilización a psicoestimulantes. Un esquema de los efectos bioquímicos de psicoestimulantes en el ATV se ilustra en la figura 3.

\section{Glutamato, calcio y sensibilización}

Los receptores ionotrópicos de glutamato (NMDA y AMPA) y los canales de calcio del tipo L de las neuronas dopaminérgicas

del ATV desempeñan un papel decisivo en la sensibilización. La mayor liberación de glutamato mediada por receptores presinápticos $D_{1}$ de dopamina regula al alza los canales de calcio tipo L en las neuronas de dopamina del ATV [16]. Además, la despolarización de las neuronas de dopamina antes comentada origina la apertura de canales NMDA, que normalmente están inactivos, bloqueados por magnesio, contribuyendo en conjunto a una mayor entrada de calcio [17]. El calcio actúa como una molécula 'gatillo' y su entrada induce una activación de vías intracelulares dependientes de este ión, por ejemplo, uniéndose a calmodulina, que regula la fosforilación y activación de diversas enzimas, como la proteincinasa C (PKC) o las calmodulinacinasas I, II y IV (CaMK I, II y IV). Entre éstas destaca la CaMK II, que permanece fosforilada (activa) largo tiempo, incluso tras la ausencia de calmodulina unida a calcio.

Una vez activada, la CaMK II puede fosforilar a su vez canales AMPA, receptores NMDA, canales de calcio tipo L, la enzima tirosinhidroxilasa -sintetizadora de dopamina- y sinapsina I, que facilita el almacenamiento vesicular de dopamina [18-19]. Es evidente que todos estos fenómenos amplifican el proceso de sensibilización mediada por calcio. De hecho, la administración intra-ATV de un inhibidor de la CaMK II, el KN-93, bloquea el desarrollo de sensibilización a cocaína [20]. La fosforilación de receptores NMDA y AMPA mediaría el desarrollo de potenciación a largo plazo (LTP) de las neuronas dopaminérgicas del ATV, y probablemente en otras áreas del circuito, como el núcleo accumbens.

La CaMK II, vía Ras, también estimula la vía de cinasas tipo MAP. Así, Ras activa la enzima Raf (MAP cinasa tipo 3), que fosforila MEK (MAP cinasa cinasa), que a su vez fosforila y activa ERK. En este punto se cree que han de participar factores tróficos, pues la cascada Ras/MAP cinasas se activa también por estimulación del receptor tirosincinasa $\mathrm{C}$ (trk C) o de recep- 


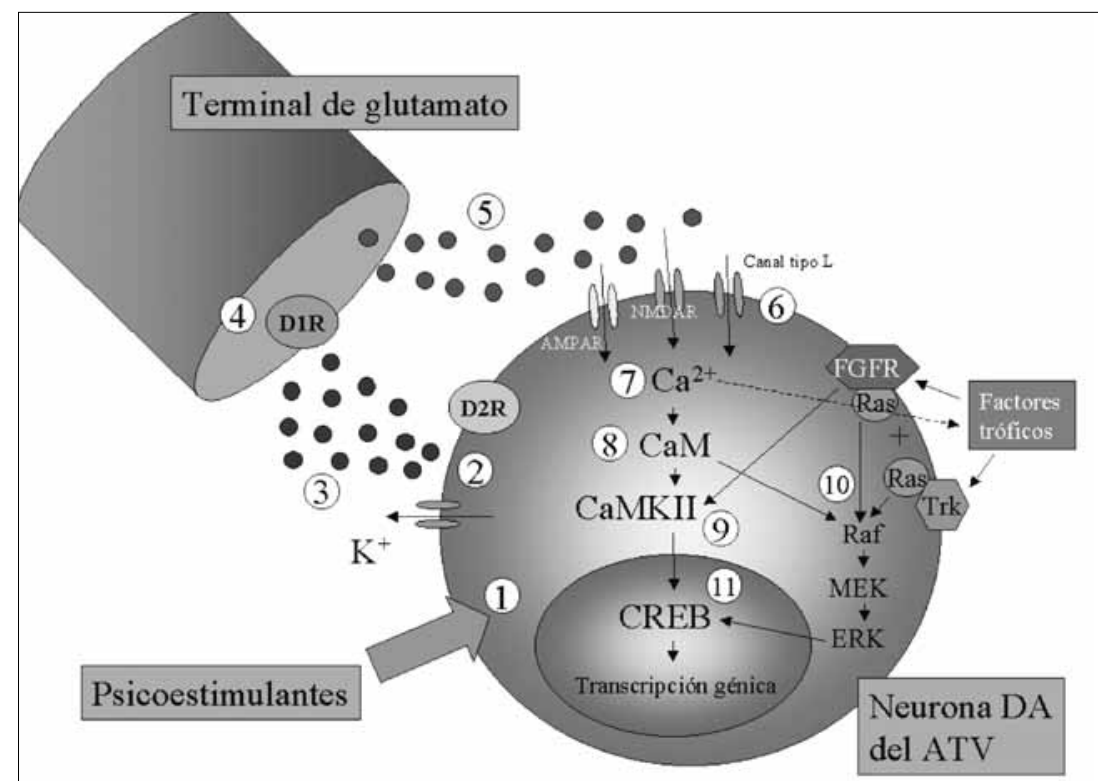

Figura 3. Eventos bioquímicos que tienen lugar en las neuronas dopaminérgicas del área teg mental ventral (ATV) por la acción de drogas psicoestimulantes, durante la inducción de la sensibilización dependiente de dopamina. Los efectos se ordenan de modo que: 1 La acción psicoestimulante sobre las neuronas de dopamina (DA) del ATV conlleva una mayor liberación de dopamina extracelular; 2 . Se desensibilizan los receptores $D_{2}$ (D2R) y disminuye el flujo de salida de potasio, lo que despolariza la neurona; 3. Aumenta la secreción de dopamina extracelular; 4. Ello ocasiona una regulación al alza de receptores D1 presinápticos de dopamina (D1R) en las terminales de glutamato; 5 . Aumenta la liberación de glutamato; 6 . El glutamato activa receptores AMPA, NMDA (activados por despolarización) y de calcio tipo L; 7. Se estimula una mayor entrada de calcio a la célula de dopamina; 8. El calcio se une a la calmodulina (CaM); 9. Se activa la calmodulincinasa tipo II (CaMK II); 10. Hay también una mayor liberación de factores tróficos que actúan sobre receptores, como son los del tipo tirosincinasa (trk) o de FGF (FGFR), y se activa la vía dependiente de la proteína Ras (cinasas tipo MAP), donde también interviene la CaM de modo cooperativo, así como otras vías; 11 Las vías de CaMK II y cinasas tipo MAP convergen y se estimula la expresión del factor CREB, el cual actúa sobre el ADN nuclear y facilita procesos de plasticidad neuronal, fosforilación de proteínas y enzimas, etc.

tores FGFR para FGF, y factores tróficos como FGF-2 o neurotrofina-3 (NT-3) modulan la sensibilización a psicoestimulantes. La infusión de NT-3 en el ATV ocasiona un aumento de la sensibilización a cocaína, y los anticuerpos anti-NT-3 la bloquean [21]. Es posible que tanto la activación estimulada por entrada de calcio como factores neurotróficos como NT-3 y FGF-2 participen de modo cooperativo en el proceso de sensibilización, y que ambos procesos sean necesarios para ésta. Es evidente que otras vías independientes de Ras han de actuar. Por ejemplo, los FGF activan también la vía de la fosfolipasa $\mathrm{C} \gamma$, que también induce las formas fosforiladas de ERK2 y Jun cinasas $[22,23]$. Es interesante el hecho de que el aumento de calcio citosólico puede inducir la liberación de factores tróficos como FGF-1 o FGF-2 en el ATV [24], o que la dopamina y factores como FGF-1 han de actuar cooperativamente para facilitar la sensibilización [25,26]. En el laboratorio del autor se ha observado que el FGF-1 del ATV media un efecto sensibilizador.

\section{Dianas intracelulares de CaM y MAP cinasas}

Una diana común de las vías CaM y MAP cinasas es el factor de transcripción CREB, involucrado en procesos de plasticidad neuronal. Se sabe que una sola inyección de anfetamina en el ATV induce un incremento de los niveles de CREB [27]. Las enzimas CaM activan CREB fosforilándola en el residuo 133 de serina. Dianas de CREB son, por ejemplo, las proteínas de la familia Fos y la neurotensina, que se expresan en el ATV [28].
El aumento de CREB en el ATV y NAc se ha postulado como un mecanismo de neuroadaptación, pues disminuye las propiedades reforzadoras de los psicoestimulantes [29]. Sin embargo, también participa en cambios proteicos y enzimáticos a largo plazo que subyacen a la adicción. Así el aumento de CREB activa la enzima tirosinhidroxilasa, lo que explica que la síntesis de dopamina aumenta en el ATV y sus terminales durante el desarrollo de la sensibilización, y fosforila la sinapsina I, lo que induce un mayor almacenamiento de dopamina en las vesículas de secreción [30].

Otros factores de transcripción aumentados son los de la familia Fos (a través de CREB u otras vías de cinasas como PKC), que se unen a miembros de la familia Jun para formar proteínas activadoras-1 (AP-1), que regulan la expresión genética. Entre estos factores destaca c-Fos, Fras-1, Fras-2 y $\delta$ FosB. Todos aumentan de modo transitorio tras el consumo de droga, excepto $\delta$ FosB que se va acumulando en el citoplasma, razón por la cual es un serio candidato para explicar cambios a largo plazo en el proceso adictivo. Experimentalmente se ha demostrado que este factor es crítico en el desarrollo de la sensibilización, y que además podría relacionarse con los fenómenos de depresión a largo plazo (LTD) en el estriado ventral porque reduce la permeabilidad de calcio en canales AMPA y hace menos excitables las neuronas [29].

Finalmente, hay otros factores de transcripción involucrados, como son el Egr1-3 y el Nac-1, que aumentan en el núcleo accumbens durante la sensibilización a cocaína [31]. Los glucocorticoides también podrían participar en cambios crónicos porque actúan también como factores de transcripción.

\section{En el estriado tiene lugar la transición desde la inducción a la expresión de la sensibilización}

Los procesos bioquímicos involucrados en la expresión de la sensibilización son menos conocidos. En la expresión participan de modo importante el núcleo accumbens, la corteza prefrontal, la amígdala y el estriado dorsal, regiones incluidas en el bucle corticoestriatoamigdalino [32]. Se sabe que la expresión de la sensibilización requiere la activación de proyecciones de glutamato desde la corteza prefrontal dorsal hasta el centro o core del núcleo accumbens. Además, se requiere una hiperactividad dopaminérgica en el núcleo accumbens y la amígdala, aunque probablemente hay una pérdida del tono inhibitorio dopaminérgico en la corteza prefrontal, lo que a su vez disminuiría el control inhibitorio de ésta sobre el núcleo accumbens y otros centros, principalmente la amígdala en su porción basolateral (BLA). Se ha descrito que el aumento de dopamina en la corteza prefrontal facilita la actividad de las neuronas de ésta (se sitúan en actividad rítmica de disparo o up-state), lo que disminuye la actividad neuronal en la BLA y, además, anula la entrada corticosensorial sobre la BLA [33,34]. Por tanto, en el estado sensibilizado, se pierde la acción inhibitoria de la corteza pre- 
frontal sobre la BLA (por probable hipoactividad dopaminérgica en la corteza prefrontal), además de aumentar la actividad de la BLA por incremento de la acción dopaminérgica desde el ATV. Estos hechos conllevan una mayor actividad glutamatérgica desde la BLA sobre el núcleo accumbens, lo que podría facilitar cambios plásticos en éste que reforzarían la sensibilización. Estos cambios plásticos se definirían en forma de establecimiento de circuitos funcionales nuevos o engramas, cuya activación podría ser la base neuronal de la 'motivación' por la droga. Todos estos hechos neuroquímicos concuerdan con la teoría actual sobre la adicción que combina un aumento de respuestas condicionadas asociadas al uso de la droga, junto a una pérdida de control inhibitorio que daría lugar a la impulsividad del consumo [35].

El estriado, tanto en su porción ventral (núcleo accumbens) como dorsal, desempeña un papel crítico en los cambios adaptativos al consumo crónico de droga que llevan a la adicción. La inicial actividad dopaminérgica aumentada desde el ATV sobre el núcleo accumbens facilitaría la formación de aprendizaje pauloviano e instrumental que caracteriza a la adicción, el cual se consolidaría en forma de hábito en el estriado dorsal. Estos hechos se relacionan también con la sensibilización dopaminérgica mantenida [36] y con la aparición de hipersensibilidad de receptores $\mathrm{D}_{1}$ en el núcleo accumbens tras la administración crónica de psicoestimulantes. El aumento de sensibilización locomotora por hipersensibilidad $\mathrm{D}_{1}$ se demuestra porque los ratones mutantes sin receptores $D_{1}$ no denotan un incremento progresivo de la locomoción tras el tratamiento repetido con morfina [37]. Los receptores D3 en el núcleo accumbens también se sensibilizan tras la administración de psicoestimulantes como la cocaína. Se cree que la acción dopaminérgica (a través de receptores D1 y D3) facilita el establecimiento de circuitos neuronales estables o engramas en el núcleo accumbens, pues la dopamina 'da paso' a la acción glutamatérgica desde la corteza prefrontal y la BLA sobre las neuronas del núcleo accumbens (y probablemente desde el hipocampo), activándolas y situándolas en estado 'alto' (up-state) [38]. La formación de nuevos engramas neuronales es un requisito para el establecimiento de 'motivación' de búsqueda de droga (desempeñando un papel crítico el núcleo accumbens), así como de hábitos motores anómalos (teniendo en este caso el estriado dorsal el papel predominante).

La hiperactividad dopaminérgica en el estriado, tanto ventral como dorsal, se asocia a una mayor síntesis y liberación de dopamina en las terminales mesolímbicas y nigroestriatales, relacionada con mecanismos similares a los ya explicados respecto a la sensibilización en el ATV. O sea, existiría una fosforilación de proteínas como tirosinhidroxilasa y sinapsina I a través del incremento de calcio intracitoplásmico y de las vías de cinasa como CaMK II y PKC [30]. De este modo, el consumo continuado de la droga establece circuitos motores estables o engramas probablemente diseñados para el aprendizaje del consumo [39].

El uso compulsivo de la droga se caracteriza por ser una conducta inflexible de hábito que persiste a pesar de su coste negativo considerable sobre el adicto, y se estimula fácilmente por estímulos asociados al consumo [40]. Una hipótesis establece que, una vez se consolidan las actividades neuronales del circuito corticoestriatoamigdalino que participan en el aprendizaje de consumo de la droga (incluyendo aspectos cognitivos de recompensa), se generaría una espiral ventrodorsal en el estriado de tal modo que se 'transfiere' la información al estriado dorsal y se consolidan circuitos de hábito motor muy estables. Los me- canismos moleculares no se conocen con precisión, pero parecen ser semejantes a los que suceden en el núcleo accumbens. En todo este proceso, la sensibilización dopaminérgica mantenida sería fundamental. A este respecto es muy interesante que, en monos, se ha observado que la expresión del transportador de dopamina aumenta desde el núcleo accumbens al estriado dorsal en la transición del estado agudo al crónico de administración de cocaína, lo que podría ser un marcador de la transferencia de información entre el estriado ventral y el dorsal [41].

\section{¿Es la adicción a psicoestimulantes una forma de aprendizaje anómalo?}

Se ha detectado el desarrollo de LTP o LTD en el estriado dorsal durante la adicción a psicoestimulantes [42], lo que es muy importante porque ambos fenómenos (muy estudiados en procesos de aprendizaje) modifican de modo permanente la actividad sináptica, lo que explicaría la consolidación de la adicción. La LTP estriatal podría relacionarse con una fase prolongada de actividad en la sustancia negra por el uso de la droga, mientras que en la LTD mediaría una actividad tónica mantenida [43]. Estos hechos resultan de gran interés porque involucran a la actividad dopaminérgica de la sustancia negra, y no del ATV, en la adicción crónica. Respecto a la actividad glutamatérgica de origen cortical, una mayor actividad glutamatérgica ocasionaría LTP, pero una menor actividad de glutamato participaría en la LTD. Ambos procesos parece que se producen de modo paralelo, afectando a distintas poblaciones de neuronas en el estriado. Cómo estos hechos afectan a la conducta y a los hábitos motores es algo que no se conoce todavía. Se sabe que los cannabinoides endógenos del receptor CB1, como la anandamida, participan en estos procesos. Una mayor o menor liberación de anandamida (cuya liberación se estimula por la acción de la dopamina sobre receptores $\mathrm{D}_{2} \mathrm{y}$, por tanto, se relaciona con el consumo de la droga) disminuye o incrementa, respectivamente, la liberación de glutamato en el estriado, lo que modula la aparición de LTD o LTP [44]. De hecho, la liberación de anandamida endógena participa en la LTD en el núcleo accumbens, disminuyendo la liberación de glutamato de terminales desde la corteza prefrontal [45]. La conducta de búsqueda de cocaína puede precipitarse en animales mediante agonistas $\mathrm{D}_{2}$ pero no $\mathrm{D}_{1}$, lo que podría relacionarse con la activación por cannabinoides endógenos [46].

El uso continuado de psicoestimulantes también produce cambios morfológicos en el estriado, como son el aumento del número de espinas dendríticas, la aparición de nuevas dendritas o el establecimiento de uniones tipo gap $[47,48]$. Estos cambios morfológicos son unos claros indicadores de cambios funcionales, y además persisten durante largo tiempo. Es evidente que deben desempeñar un papel en las profundas alteraciones conductuales de la adicción crónica.

\section{Neurobiología de la pérdida de control}

La transición desde el consumo controlado de droga hasta el hábito compulsivo depende de modo crítico de la pérdida del control ejecutivo de la corteza prefrontal sobre el estriado dorsal. Este fenómeno desempeñaría un papel paralelo al del establecimiento de hábitos y aprendizaje estímulo-respuesta en el estriado, comentado con anterioridad. Se sabe que hay un descenso funcional en la actividad de la corteza prefrontal en adictos a la cocaína y la anfetamina $[49,50]$. Aunque no existe confirmación experimental de esta hipótesis, en animales de labora- 
torio la destrucción de la corteza prefrontal facilita la conducta compulsiva de búsqueda de droga y, lo que es muy interesante, sin modificar la conducta de búsqueda de alimento [51]. La hipoactividad prefrontocortical influiría no sólo en el establecimiento de engramas neuronales en el estriado -que generarían hábitos de consumo anómalos, como se ha comentado-, sino también en la pérdida de control consciente sobre los propios actos por parte del sujeto, facilitando la pérdida de control que es característica de la adicción avanzada. En definitiva, la corteza prefrontal desempeña un papel decisivo tanto en la formación de hábitos patológicos en el adicto como en el mantenimiento de éstos. Esta pérdida de control también podría subyacer a los fenómenos de craving o deseo de droga que sufre el antiguo adicto, y que son una causa importante de la recaída en el consumo.

\section{CONCLUSIONES}

Las drogas psicoestimulantes son sustancias capaces de reducir los umbrales de alerta o de vigilia e inducen dependencia. Incluyen anfetamínicos, alcaloides naturales como la cocaína y las metilxantinas. La dependencia se manifiesta por fenómenos de base neurobiológica como son la sensibilización y la tolerancia. La neurobiología de la sensibilización se conoce con más detalle e incluye dos fases: una de inducción inicial y otra de consolidación o expresión. En la fase de inducción desempeñan un papel crítico el circuito mesocorticolímbico dopaminérgico y la neurotransmisión dopaminérgica y de glutamato en el tegmento ventral. Los psicoestimulantes inducen un incremento en la actividad de dopamina en el tegmento ventral del mesencéfalo, facilitada por despolarización neuronal, y estimulan receptores $\mathrm{D}_{1}$ presinápticos que ocasionan una mayor liberación local de glutamato, lo que a su vez estimula aún más las neuronas de dopamina del ATV, constituyendo estos hechos un ciclo fundamental en la inducción de la sensibilización. En la fase de expresión se crean hábitos adictivos de conducta por cambios permanentes en el bucle corticoestriatoamigdalino. Todo ello lleva a una adicción consolidada, considerada una forma de aprendizaje anómalo, y a una pérdida de control sobre la conducta por parte del adicto. La transición desde el consumo controlado de droga hasta el hábito compulsivo depende de modo crítico de la pérdida del control ejecutivo de la corteza prefrontal sobre el estriado dorsal.

\section{BIBLIOGRAFÍA}

1. Seiden LS, Kabol KE, Ricaurte GA. Amphetamine: effect on cathecolamine systems and behavior. Annu Rev Pharmacol Toxicol 1993; 32 : $335-50$.

2. Ritz MC, Lamb RJ, Goldberg SR, Kuhar MJ. Cocaine receptors on dopamine transporters are related to self-administration of cocaine. Science 1987; 237: 1219-23.

3. Kalivas PW, Duffy P. Repeated cocaine administration alters extracellular glutamate in the ventral tegmental area. J Neurochem 1998; 70: 1497-502.

4. Robinson TE, Berridge KC. The neural basis of drug craving: an incentive-sensitization theory of addiction. Brain Res Rev 1993; 18: 247-91.

5. Robinson TE, Berridge KC. The psychology and neurobiology of addiction: an incentive-sensitization view. Addiction 2000; 95: S91-117.

6. Carlezon WA, Boundy VA, Haile CN, Lane SB, Kalb RG, Neve RL, et al. Sensitization to morphine induced by viral-mediated gene transfer. Science 1997; 277: 812-4.

7. Nestler EJ, Aghajanian GK. Molecular and cellular basis of addiction. Science 197; 278: 58-63.

8 Kalivas PW, Stewart J. Dopamine transmission in the initiation and expression of drug- and stress-induced sensitization of motor activity. Brain Res Rev 1991; 16: 223-44.

9. Parsons LH, Justice JB. Serotonin and dopamine sensitization in the nucleus accumbens, ventral tegmental area and dorsal raphe nucleus following repeated cocaine administration. J Neurochem 1993; 61: $1611-9$.

10. Nestler EJ, Terwilliger RZ, Walker JR, Sevarino KA, Duman RS. Chronic cocaine treatment decreases levels of the $G$ protein subunits Gia and Goa in discrete regions of the rat brain. J Neurochem 1990; 55 : 1079-82.

11. Henry DJ, Xu XT, White FJ. Adaptations in the mesoaccumbens dopamine system resulting from repeated administration of dopamine $D_{1}$ and $D_{2}$ receptor-selective agonists: reliance to cocaine sensitization. Psychopharmacology 1998; 140: 233-42.

12. Stewart J, Vezina P. Microinjections of SCH-23390 into the ventral tegmental area and substantia nigra pars reticulate attenuate the development of sensitization to the locomotor activating effects of systemic amphetamine. Bran Res 1989; 495: 401-6.

13. Vezina $P$. $D_{1}$ dopamine receptor activation is necessary for the induction of sensitization by amphetamine in the ventral tegmental area. $\mathrm{J}$ Neurosci 1996; 16: 2411-20.

14. Pierce RC, Born B, Adams M, Kalivas PW. Repeated intra-ventral tegmental area administration of SKF-38393 induces behavioral and neurochemical sensitization to a subsequent cocaine challenge. J Pharmacol Exp Ther 1996; 278: 384-92.

15. Carr DB, Sesack SR. Projections from the rat prefrontal cortex to the ventral tegmental area: target specificity in the synaptic associations with mesoaccumbens and mesocortical neurons. J Neurosci 2000; 20: 3864-73.
16. Wolf ME, Xue CJ. Amphetamine-induced glutamate efflux in the rat ventral tegmental area is prevented by MK-801, SCH-23390, and ibotenic acid lesions of the prefrontal cortex. J Neurochem 1999; 73: 1529-38.

17. Jones SW. Overview of voltage-dependent calcium channels. J Bioenerg Biomembr 1998; 30: 299-312.

18. Bayer KU, De KP, Leonard AS, Hell JW, Schulman H. Interaction with the NMDA receptor locks CaMII in an active conformation. Nature 2001; 411: 801-5.

19. Poncer JC, Esteban JA, Malinov R. Multiple mechanisms for the potentiation of AMPA receptor-mediated transmission by alpha-Ca2+l calmodulin-dependent protein kinase II. J Neurosci 2002; 22: 4406-11.

20. Licata SC, Pierce RC. The roles of calcium/calmodulin-dependent and Ras/mitogen-activated protein kinases in the development of psychostimulant-induced behavioral sensitization. J Neurochem 2003; 85: 14-22.

21. Flores C, Stewart J. Basic fibroblast growth factor as a mediator of the effects of glutamate in the development of long-term sensitization to stimulant drugs: studies in the rat. Psychopharmacology 2000; 151: $152-65$.

22. Mohammadi M, Honegger AM, Rotin D, Fischer R, Bellot F, Li W, et al. A tyrosine-phosphorylated carboxy-terminal peptide of the fibroblast growth factor receptor (Flg) is a binding site for the $\mathrm{SH} 2$ domain of phospholipase C-gamma 1. Mol Cell Biol 1991; 11: 5068-78.

23. Reuss B, Von Bohlen und Halbach O. Fibroblast growth factors and their receptors in the central nervous system. Cell Tissue Res 2003; 313: $139-57$.

24. Kinokawa H, Jikou T, Nitta A, Furukawa Y, Hashimoto M, Fukumitsu $\mathrm{H}$, et al. Cyclic AMP/protein kinase A signal attenuates $\mathrm{Ca}^{2+}$-induced fibroblast growth factor-1 synthesis in rat cortical neurons. J Neurosci Res 2004; 77: 487-97.

25. Stull ND, Iacovitti L. Acidic fibroblast growth factor and catecholamines synergistically up-regulate tyrosine hydroxylase activity in developing and damaged dopamine neurons in culture. J Neurochem 1996; 67: $1519-24$

26. Laviolette SR, Gallegos RA, Henriksen SJ, Van der Kooy D. Opiate state controls bi-directional reward signalling via $\operatorname{GABA}(\mathrm{A})$ receptors in the ventral tegmental area. Nat Neurosci 2004; 7: 160-9.

27. Dalley JW, Thomas KL, Howes SR, Tsai TH, Aparicio-Legarza ML, Reynolds GP, et al. Effects of excitotoxic lesions of the rat prefrontal cortex on CREB regulation and presynaptic markers of dopamine and amino acid function in the nucleus accumbens. Eur J Neurosci 1999; 11: $1265-74$.

28. Stephenson CP, Hunt GE, Toplle AN, McGregor IS. The distribution of 3,4-methylenedioxymetamphetamine 'ecstasy'-induced c-fos expression in rat brain. Neuroscience 1999; 92: 1011-23.

29. Nestler EJ. Molecular basis of long-term plasticity underlying addiction. Nat Rev Neurosci 2001; 2: 119-28.

30. Iwata SI, Hewlett GHK, Ferell ST, Kantor L, Gnegy ME. Enhanced 
dopamine release and phophorylation of synapsin and neuromodulin in striatal synaptosomes after repeated amphetamine. J Pharmacol Exp Ther 1997; 283: 1445-52.

31. Kalivas PW, Duffy P, Mackler SA. Interrupted expression of Nac-1 augments the behavioral responses to cocaine. Synapse $1999 ; 33: 153-9$.

32. Pierce RC, Kalivas PW. A circuitry model of the expression of behavioral sensitization to amphetamine-like psychostimulants. Brain Res Rev 1997; 25: 192-216.

33. Lewis B, O'Donnell P. Ventral tegmental area afferents to the prefrontal cortex maintain membrane potential 'up' states in pyramidal neurons via $\mathrm{D}_{1}$ dopamine receptors. Cereb Cortex 2000; 10: 1168-75.

34. Rosencranz JA, Grace AA. Dopamine attenuates prefrontal cortical suppression of sensory inputs to the basolateral amygdala of rats. J Neurosci 2001; 21: 4090-103.

35. Robbins TW, Everitt BJ. Drug addiction: bad habits add up. Nature 1999; 398: 567-70.

36. Di Chiara G, Imperato A. Drugs abused by humans preferentially increase synaptic dopamine concentrations in the mesolimbic system of freely moving rats. Proc Natl Acad Sci USA 1988; 85: 5274-8.

37. Moratalla R, Xu M, Tonegawa S, Graybiel AM. Cellular responses to psychomotor stimulant and neuroleptic drugs are abnormal in mice lacking the $\mathrm{D}_{1}$ dopamine receptor. Proc Natl Acad Sci USA 1996; 93: 14928-33.

38. Fernández-Espejo E. Bases neurobiológicas de la drogadicción. Rev Neurol 2002; 34: 659-65.

39. Berke JD, Hyman SE. Addiction, dopamine and the molecular mechanisms of memory. Neuron 2000; 25: 515-32.

40. Childress AR, Ehrman R, Roohsenow DJ, Robbins SJ, O'Brien CP. Classically conditioned factors in drug dependence. In Subman RB, Langard JG, eds. Substance abuse. Baltimore: Williams \& Wilkins; 1992. p. 56-69.

41. Letchworth SR, Nader MA, Smith HR, Friedman DP, Porrino LJ. Pro-

\section{NEUROBIOLOGÍA DE LA ADICCIÓN A PSICOESTIMULANTES}

Resumen. Introducción y desarrollo. Las drogas psicoestimulantes incluyen anfetamínicos, alcaloides naturales como la cocaína y metilxantinas. Inducen una fuerte dependencia, que se manifiesta por fenómenos de base neurobiológica como la sensibilización y la tolerancia. La sensibilización se está estudiando experimentalmente e incluye dos fases: una de inducción inicial y otra de consolidación o expresión. En la fase de inducción desempeñan un papel crítico el circuito mesocorticolímbico dopaminérgico y la neurotransmisión dopaminérgica y de glutamato en el tegmento ventral. En la fase de expresión se crean hábitos adictivos de conducta por cambios permanentes en el bucle corticoestriatoamigdalino. Conclusión. Todo ello lleva a una adicción consolidada, considerada como una forma de aprendizaje anómalo, y a una pérdida de control sobre la conducta por parte del adicto. [REV NEUROL 2006; 43: 147-54]

Palabras clave. Adicción. Dopamina. Droga. Glutamato. Hábito. Psicoestimulante. Sensibilización. gression of changes in dopamine transporter binding site density as a result of cocaine self-administration in Rhesus monkeys. J Neurosci 2001; 21: 2799-807.

42. Wolf ME. Addiction and glutamate-dependent plasticity. In Herman BH, Frankenheim J, Litten R, Sheridan PH, Weight FF, Zukin SR, eds. Glutamate and addiction. Totowa, NJ: Humana Press; 2002. p. 127-41.

43. Reynolds JN, Wickens JR. Dopamine-dependent plasticity of corticostriatal synapses. Neural Netw 2002; 15: 507-21.

44. Gerdeman GL, Partridge JG, Lupica CR, Lovinger DM. It could be habit forming: drugs of abuse and striatal synaptic plasticity. Trends Neurosci 2003; 26: 184-92.

45. Robbe D, Kopf M, Remaury A, Bockaert J, Manzoni OJ. Endogenous cannabinoids mediate long-term synaptic depression in the nucleus accumbens. Proc Natl Acad Sci USA 2002; 99: 8384-8.

46. Self DW, Barnhardt WJ, Lehman DA, Nestler EJ. Opposite modulation of cocaine-seeking behavior by $\mathrm{D}_{1}$ and $\mathrm{D}_{2}$-like dopamine receptor agonists. Science 1996; 271: 1586-9.

47. Onn SP, Grace AA. Amphetamine withdrawal alters bistable states and cellular coupling in rat prefrontal cortex and nucleus accumbens neurons recorded in vivo. J Neurosci 2000; 20: 2332-45.

48. Robinson TE, Gorny G, Mitton E, Kolb B. Cocaine self-administration alters the morphology of dendrites and dendritic spines in the nucleus accumbens and neocortex. Synapse 2001; 39: 257-66.

49. Volkow ND, Fowler JS. Addiction, a disease of compulsion and drive: involvement of the prefrontal cortex. Cereb Cortex 2000; 10: 318-25.

50. Goldstein RZ, Volkow ND, Wang GJ, Fowler JS, Rajaram S. Addiction changes orbitofrontal gyrus function: involvement in response inhibition. Neuroreport 2001; 12: 2595-9.

51. Weisenborn R, Robbins TW, Everitt BJ. Effects of medial prefrontal or anterior cingulate cortex lesion on responding for cocaine under fixedratio and second-order schedules of reinforcement in rats. Psychopharmacology 1997; 134: 242-57.

\section{NEUROBIOLOGIA DA HABITUAÇÃO A PSICO-ESTIMULANTES}

Resumo. Introdução e desenvolvimento. As drogas psico-estimulantes incluem anfetamínicos, alcalóides naturais como a cocaína e metilxantinas. Induzem uma forte dependência, que se manifesta por fenómenos de base neurobiológica como a sensibilização e a tolerância. A sensibilização está a ser estudada experimentalmente e inclui duas fases: uma de indução inicial e outra de consolidação ou expressão. Na fase de indução desempenham um papel crítico o circuito mesocorticolímbico dopaminérgico e a transmissão neurológica dopaminérgica e de glutamato no tegmento ventral. Na fase de expressão são criados hábitos aditivos de conduta por alterações permanentes no anel cortico-estriato-amigdalino. Conclusão. Tudo conjugado leva a uma habituação consolidada, considerada como uma forma de aprendizagem anómala e a uma perda de controlo sobre os comportamentos de consumo. [REV NEUROL 2006; 43: 147-54]

Palavras chave. Dopamina. Droga. Glutamato. Hábito. Habituação. Psico-estimulante. Sensibilização. 